\title{
Tumor Findings Laterality
}

National Cancer Institute

\section{Source}

National Cancer Institute. Tumor Findings Laterality. NCI Thesaurus. Code C119931.

A qualifier for the side of the body the tumor findings assessment is performed. 